\title{
FORMULATION AND CHARACTERIZATIONS OF SELF-NANOEMULSIFYING DRUG DELIVERY SYSTEM OF EXTRACT PETIVERIA ALLIACEA (SINGAWALANG) LEAVES
}

\author{
ARIFA MUSTIKA $^{1 *}$, NURMAWATI FATIMAH ${ }^{1}$, GADIS MEINAR SARI ${ }^{2}$ \\ ${ }^{1}$ Department of Pharmacology and Therapy, Faculty of Medicine, Universitas Airlangga, Prof. Moestopo 47, Surabaya, Indonesia. ${ }^{2}$ Department \\ of Physiology, Faculty of Medicine, Universitas Airlangga, Prof. Moestopo 47, Surabaya, Indonesia. Email: arifa-m@fk.unair.ac.id
}

Received: 19 December 2018, Revised and Accepted: 22 July 2019

\section{ABSTRACT}

Objective: Formulation of Singawalang leaves extract should be considered because the extract contains a variety of compounds so that there may be a competitor in the absorption process and will cause the absorption of active ingredients in the gastrointestinal decline. One way to increase the absorption and disposition of active ingredients on target organs is to use a nanoparticle formulation. Therefore, this study will conduct research on self-nanoemulsifying drug delivery system (SNEDDS) formulation of Singawalang (Petiveria alliacea) leaves extract.

Methods: The systems were developed by investigating the solubility Singawalang leaves extract in various carrier oil, the suitable surfactant, and cosurfactant, construction of SNEDDS of Singawalang leaves extract and characterization of droplet size through particle size analyzer and transmission electron microscopy.

Results: The results of this study indicate that the optimum carrier oils for Singawalang leave extract are miglitol and virgin coconut oil (VCO), the compatible surfactant component is tween 80 and the compatible cosurfactant is propylene glycol (PG). The average droplet size is $13 \mathrm{~nm}$ and polydisperse index 0,004 and 0,006 .

Conclusion: It can be concluded, the present study demonstrated that the optimum SNEDDS formulations of Singawalang leave extract are the mixture of VCO, tween $80, \mathrm{PG}$ at ratio 1:8:1 and miglitol, tween 80 , and $\mathrm{PG}$ at ratio 2:5:3.

Keywords: Petiveria alliacea, Self-nanoemulsifying drug delivery system, Miglitol, Virgin coconut oil.

(C) 2019 The Authors. Published by Innovare Academic Sciences Pvt Ltd. This is an open access article under the CC BY license (http://creativecommons. org/licenses/by/4. 0/) DOI: http://dx.doi.org/10.22159/ijap.2019.v11s5.T0050

\section{INTRODUCTION}

Singawalang (Petiveria alliacea) is a plant widely found in Indonesia and empirically used by residents to treat various diseases such as diabetes and bleeding cough and is also used to protect plants from pests. The ethanol extract of Singawalang leaves has the ability to lower blood sugar levels [1,2]. Mustika et al., 2015, also showed that extract of Singawalang leaves decreased blood sugar level in the mouse model of type 2 diabetes mellitus (T2DM) with the optimum dosage of $360 \mathrm{mg} / \mathrm{kg} \mathrm{BW}$ and also increased 5' adenosine monophosphateactivated protein kinase expression on liver [3]. This phenomenon raises the hope that the extract can be used as a phytopharmaca drug in the management of T2DM.

The extract of Singawalang leaves contains a complex of active compounds so that there may be a competition between several active compounds in the absorption process and will cause the absorption of active compounds in the gastrointestinal decline. Herbal medicine also has some problems such as instability and solubility formulation, low absorption because unable to cross the lipid membranes of the cells, larger molecular size, numerous large of chemical molecules, degradation during gastric emptying, and extensive metabolism $[4,5]$. Therefore, the formulation of drug dosage forms and active material delivery systems plays an important role in determining their therapeutic effects. Therefore, it is necessary to do good research on the formulation of the dosage form of leaves extract Singawalang.

The nanomaterials can expressively enrich the pharmacokinetics, pharmacodynamic, and therapeutic index of phytomedicines. In accordance with micrometer-sized, nanocarriers are responsible for more surface area and increase solubility, bioavailability, and enable appropriate nanomedical targeting $[4,6,7]$. The advantages for herbal medicines nanoparticles formulation are including increased solubility and bioavailability, protection from toxicity, increased pharmacological activity, increased stability, improved tissue distribution, continuous shipping, and physical protection and chemical degradation $[8,9]$. Various research has been developed to improve the formulation and delivery system that aims to increase the levels of active ingredients to target organs, one of which is by the delivery of active ingredients in the nanoparticle system $[10,11]$.

The system of lipid-based drugs has achieved increased interest in the oral route of administration of poorly bioavailable drugs. This lipid system is absorbed by lymphatic system through Peyer patch along the gastrointestinal tract. The self-nanoemulsifying drug delivery system (SNEDDS) is one of the systems for the delivery of lipid-based drugs that have now been investigated for its benefit, providing a large interfacial area to partition the drug between oil and gastrointestinal fluids. This technique increases the oral bioavailability of drugs that are difficult to dissolve by increasing solubility and keeping the drug dissolved, in small droplets of oil, throughout its transit through the digestive tract. The SNEDDS has recently emerged as an approach to improve oral solubility, dissolution, and absorption for poorly waterinsoluble drugs $[12,13]$.

SNEDDS is a type of self-emulsifying drug delivery system that contains an isotropic mixture of oil, surfactants, cosurfactants, and medicinal substances, which can form nanoemulsion in the digestive tract after oral administration. Emulsions produced with particle sizes $<100 \mathrm{~nm}$ increase the solubility of hydrophobic drugs and increase their absorption. SNEDDS is an isotropic mixture of oil, surfactants, and cosurfactants that form oil-in nanoemulsions in fine water, in mild agitation, followed by administration into aqueous media, such as gastrointestinal fluids [14]. 
Thus, considering its potential benefits, we have developed a novel SNEDDS of Singawalang leaves extract and evaluated its characterization. The aim of this study was to make a formulation of Singawalang leaves extract in a SNEDDS and their characterization. The SNEDDS were developed by investigating the solubility of Singawalang leaves extract in various carrier oil, the suitable surfactant, and cosurfactant, construction of SNEDDS of Singawalang leaves extract, and self-emulsification time and percentage transmittance in artificial gastric fluid (AGF). Furthermore, the droplet size characterization of Singawalang leaves extract was evaluated through particle size analyzer and transmission electron microscopy (TEM).

\section{MATERIALS AND METHODS}

\section{Materials}

P. alliacea leaves were collected from Balai Materia Medika (BMM) Batu, East Java, Indonesia and were determined by BMM. Ethanol $96 \%$, virgin coconut oil (VCO), sunflower, olive oil, sesame oil, fish oil, soya oil, canola oil, rice oil, corn oil, span 20 , span 80 , tween 20 , and tween 80 were used. PEG 400, propylene glycol (PG) was purchased from Brataco, miglitol from the Department of Biopharmaceutics, Faculty of Pharmacy of Universitas Gadjah Mada, Yogyakarta.

\section{Methods}

Formulation of SNEDDS of Singawalang leaves extract

Extraction of Singawalang leaves

$1000 \mathrm{~g}$ of Singawalang leaves powder has been extracted with $70 \%$ ethanol solvent. The extraction was done by maceration for 3 days.

\section{Selection of SNEDDS components}

Solubility test of carrier oil

Testing solubility of Singawalang leaves extracts in various oil. The oil used is VCO, sesame oil, olive oil, corn oil, sunflower oil, fish oil, soya oil, and migltiol. $50 \mathrm{mg}$ of ethanol extract of Singawalang leaves is put into $5 \mathrm{~mL}$ each oil gradually until saturated. The mixtures were vortexed as long as $5 \mathrm{~min}$ and sonicated during 3 times-15 $\mathrm{min}$. Solubility will be visually observed.

\section{Emulsification studies of surfactant}

A surfactant was selected on the ease of emulsification and solubility by visual. Various surfactants (span 20, span 80 , tween 20 , and tween 80 ) were selected to determine the emulsification ability of the selected oil phase. Mixture the amount of selected oil and the amount of each surfactant in the tube with ratio $1: 1$, mix it by gently shaking the tube to determine the ease of emulsion. The amount of shake is used to determine the ease of emulsion. Allow the emulsion for $2 \mathrm{~h}$, and the optical clarity of aqueous dispersion was visually observed.

\section{Emulsification studies of cosurfactant}

Cosurfactant was selected on the ease of emulsification and solubility by visual. Various cosurfactants such as PEG 200, PEG 400, and PG were tested to find an appropriate formulation. Mixture the amount of surfactant and the amount of cosurfactant in the tube with ratio 2:1, mix it by gently shaking the tube to determine the ease of emulsion. The amount of shake is used to determine the ease of emulsion. Allow the emulsion for $2 \mathrm{~h}$, and the optical clarity of aqueous dispersion was visually observed.

\section{Construction of SNEDDS}

The series of SNEDDS was formulated with varying concentrations of oil $(25-70 \% \mathrm{w} / \mathrm{w})$, surfactant $(30-75 \% \mathrm{w} / \mathrm{w})$, and cosurfactant $(0-25 \% \mathrm{w} / \mathrm{w})($ Table 1$)$ at room temperature $\left(25^{\circ} \mathrm{C}\right)$ for $72 \mathrm{~h}$. For any mixture, the total of surfactant, cosurfactant, and oil concentration added was always $100 \%$. Each formulation was homogenated with a stirrer as long as $30 \mathrm{~min}$. The suitable systems were selected based on visually observed and percentage transmittance by ultraviolet (UV)-VIS spectrophotometer at $\lambda 650 \mathrm{~nm}$.
Table 1: Solubility test of the Singawalang leaves extract in various carrier oils

\begin{tabular}{ll}
\hline Oil & Solubility \\
\hline VCO & Clear \\
Sesame & Turbid \\
Olive & Turbid \\
Corn & Clear \\
Sun Flower & Turbid \\
Fish & Turbid \\
Soya & Turbid \\
Miglitol & Clear \\
\hline
\end{tabular}

Formulation of SNEDDS of Singawalang leaves extract was prepared based on the optimum suitable composition of oil, surfactant, and cosurfactant.

\section{Loading drug}

The series of the number of ethanol extracts of Singawalang leaves (50 mg, $75 \mathrm{mg}, 125 \mathrm{mg}$, and $200 \mathrm{mg}$ ) was dissolved in $5 \mathrm{~mL}$ each Sneeds system. The formulation was homogenated by vortex $4 \mathrm{~min}$, sonicator $5 \mathrm{~min}$, and heating in the water bath at $37^{\circ} \mathrm{C}$ as long as $15 \mathrm{~min}$. The cycle was repeated 3 times. The evaluation of formulations was performed using self-emulsification time and percentage transmittance by UV-VIS spectrophotometer at $\lambda 650 \mathrm{~nm}$.

\section{Self-emulsification time and percentage transmittance of Sneed} formulation

In aquadestilata and AGF

The emulsification time was evaluated by $1000 \mu \mathrm{L}$ of formulations incorporated into the $100 \mathrm{~mL}$ aquadestilata and into the $100 \mathrm{~mL}$ AGF with temperature $37^{\circ} \mathrm{C}$ and at centrifuge at a rate of $148 \mathrm{RPM}$. Time from starting formula was inserted until dissolved all called emulsification time. A sample was evaluated percentage transmittance of UV-VIS spectrophotometer at $\lambda 650 \mathrm{~nm}$.

AGF solution was prepared by mixing $1 \mathrm{~g} \mathrm{NaCl}, 35 \mathrm{~mL} \mathrm{HCl} 37 \%$, and add aqueous until $500 \mathrm{~mL}$. Adjust the $\mathrm{pH}$ until 1, 2 by adding $\mathrm{NaOH}$. Adjust AGF solution temperature at $37^{\circ} \mathrm{C}$.

\section{Characterizations of SNEDDS of Singawalang leaves extract}

Particle size analysis

Particle size and polydispersity index were obtained using particle size analyzer (HORIBA SZ-100). The polydispersity index reflects the uniformity of particle diameter and it can be used to depict the size distribution of nanoemulsion $[15,16]$. The sensitivity range was $3-8000 \mathrm{~nm}$. The measurements were performed at $25^{\circ} \mathrm{C}$ at a fixed angle of $90^{\circ}$.

\section{TEM analysis}

The extract Singawalang leaves SNEDDS droplet was observed by a transmission electron microscope. A sample was visualized by drying it on a carbon-coated grid and stained negatively with an aqueous solution of phosphotungstic acid 2\%. After drying the phosphotungstic acid, the sample was observed under TEM [17]. Samples were analyzed at a lower accelerating voltage of $100 \mathrm{kV}$ with a smaller objective aperture to achieve the contrast. Images were captured at $\times 40,000$ magnification

\section{RESULTS AND DISCUSSION}

\section{Formulation of SNEDDS of Singawalang leaves extract}

Selection of SNEDDS components

The result showed that Singawalang leaves extract dissolved on VCO, miglitol, and corn oil (Table 1). Hence, these three oils can be used as oil components to make the nanoemulsion formulations. The result of 
the test can be concluded that the compatible surfactant used to form the nanoemulsion formulation was tween 80 , and cosurfactant was PG (Table 2).

\section{SNEDDS formulation}

The compatibility of oils, surfactants, and cosurfactants to acquire a higher transmittance was an essential foundation in the formulation of the nanoemulsion.

We choose ten compositions of SNEDDS formulation based on visual examination of oil, surfactant, and co-surfactant. The result of a visual examination, time of emulsification, and percentage transmittance are shown in Table 3.

In accordance with the results of visual observations, the emulsification time and percentage transmission, the formulas A, B, C, D, E, and F are chosen as the SNEDDS formulation.

\section{Loading drug}

The six SNEDDS formulations have been added the extract Singawalang leaves at dose 1 is $50 \mathrm{mg}$, dose 2 is $75 \mathrm{mg}$, dose 3 is $125 \mathrm{mg}$, and dose 4 is $200 \mathrm{mg}$. The result of visual observation, emulsification time, and percentage transmittance in the AGF are shown in Table 4.

\section{Characterizations of SNEDDS of extract Singawalang leaves}

The mean of droplet size and the polydispersity index of SNEDDS extract Singawalang leaves are shown in Table 5.

The morphology of optimum SNEDDS and formulation of Singawalang leaves extract by TEM are shown in Fig. 1.

In this study, VCO, corn oil, and miglitol have been chosen as the carrier oil because the extract can dissolve well into the oil. VCO has a shorter chain of $\mathrm{C}$ atoms when compared with corn oil, thereby increasing the solubility of extract. The results of this study are also in accordance with the research conducted by Tri, 2018, that the solubility of Amomum compactum in VCO is better than in corn oil [18].
The solubility and emulsification studies were carried out to identify the suitable carrier oil, surfactant, and cosurfactant for the formulation of SNEDDS of Singawalang leaves extract. The result inferred that miglitol and VCO were found to solubilize of Singawalang leaves extract, tween 80 , and span 80 as surfactant, and PG as cosurfactant. Tween 80 as a non-ionic surfactant was found to have good solubility and better emulsification ability that allowed to rapid dispersion when in contact with a biological fluid. PG is a compatible cosurfactant that it can be used to enhanced solubility and bioavailability [18].

The data in the study show that all the test compositions of carrier oil, surfactants, can be used as SNEDDS formulations. Based on the

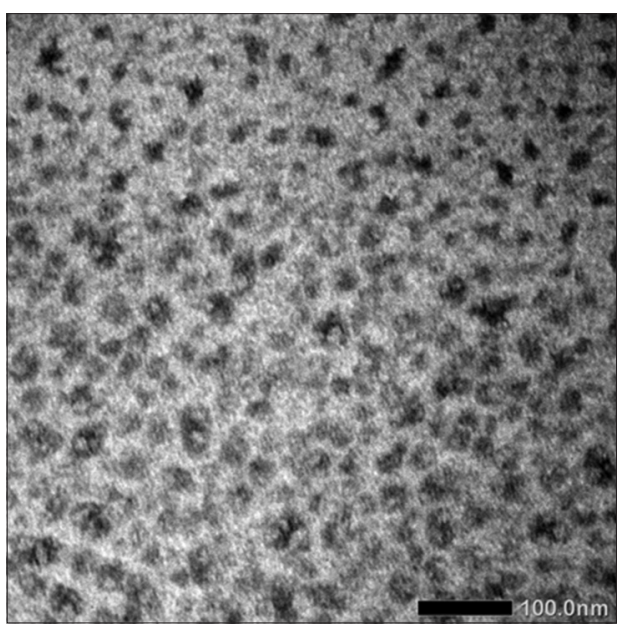

Fig. 1: The transmission electron microscopy image of droplet size of the Singawalang leaves extract self-nano emulsifying drug delivery system (SNEDDS) formula D4. The dark spherical shapes are indicated nanoparticle of SNEDDS contains Singawalang leaves extract. Magnification $\times 40,000$

Table 2: The surfactant and cosurfactant emulsification study

\begin{tabular}{|c|c|c|c|c|c|c|}
\hline \multirow[t]{2}{*}{ Surfactant } & \multicolumn{3}{|l|}{ Oil } & \multicolumn{3}{|l|}{ Cosurfactant } \\
\hline & Corn & Miglitol & VCO & PEG200 & PEG400 & PG \\
\hline Span 20 & Turbid & Turbid & & Clear homogeneous & Clear homogeneous & Turbid \\
\hline Span 80 & Turbid & Clear homogenous & Clear homogenous & Turbid & Turbid & Turbid \\
\hline Tween 20 & Turbid & Turbid & & Turbid & Turbid & Turbid \\
\hline Tween 80 & Clear homogeneous & Clear homogeneous & Clear homogeneous & Turbid & Clear homogenous & Clear homogenous \\
\hline
\end{tabular}

VCO: Virgin coconut oil, PG: Propylene glycol

Table 3: The effect of carrier oil, surfactant, and cosurfactant ratio on visual examination, time of emulsification, and percentage transmittance

\begin{tabular}{|c|c|c|c|c|c|c|c|}
\hline \multirow[t]{2}{*}{ Oil } & \multicolumn{3}{|c|}{ Ratio } & \multicolumn{3}{|l|}{ Result } & \multirow[t]{2}{*}{ Code } \\
\hline & Oil & Surfactant (tween 80) & Cosurfactant (PG) & Visual & Emulsifacation time (s) & Transmittance (\%) & \\
\hline \multirow[t]{5}{*}{ Corn } & 1 & 1 & 1 & Non-Homogeneous & $\mathrm{X}$ & $\mathrm{X}$ & \\
\hline & 1 & 7 & 2 & Turbid & $\mathrm{X}$ & $\mathrm{X}$ & \\
\hline & 2 & 5 & 3 & Turbid & $\mathrm{X}$ & $\mathrm{X}$ & \\
\hline & 2 & 6 & 2 & Turbid & $\mathrm{X}$ & $\mathrm{X}$ & \\
\hline & 1 & 8 & 1 & Turbid & $\mathrm{X}$ & $\mathrm{X}$ & \\
\hline \multirow[t]{5}{*}{ VCO } & 1 & 1 & 1 & Turbid & $\mathrm{X}$ & $\mathrm{X}$ & \\
\hline & 1 & 7 & 2 & Clear & 14 & 95,5 & A \\
\hline & 2 & 5 & 3 & Turbid & $\mathrm{X}$ & $\mathrm{X}$ & \\
\hline & 2 & 6 & 2 & Turbid & $\mathrm{X}$ & $\mathrm{X}$ & \\
\hline & 1 & 8 & 1 & Clear & 23 & 95,5 & B \\
\hline \multirow[t]{5}{*}{ Miglitol } & 1 & 1 & 1 & Turbid & $\mathrm{X}$ & $\mathrm{X}$ & \\
\hline & 1 & 7 & 2 & Clear & 25 & 95,4 & $\mathrm{C}$ \\
\hline & 2 & 5 & 3 & Clear & 21 & 95,5 & $\mathrm{D}$ \\
\hline & 2 & 6 & 2 & Clear & 15 & 95,2 & $\mathrm{E}$ \\
\hline & 1 & 8 & 1 & Clear & 25 & 95,4 & $\mathrm{~F}$ \\
\hline
\end{tabular}

VCO: Virgin coconut oil, PG: Propylene glycol 
Table 4: The result of visual observation, emulsification time, and percentage transmittance of self-nanoemulsifying drug delivery system Singawalang leaves extract formulation in artificial gastric fluid

\begin{tabular}{|c|c|c|c|c|c|}
\hline Formulation & Extract (mg) & Visual & Sediment & Emulsification time (s) & Percentage transmittance $\lambda=650 \mathrm{~nm}$ \\
\hline A1 & 50 & Clear & None & $1: 23: 6$ & 60,2 \\
\hline A2 & 75 & Clear & None & $2: 02: 3$ & 69,2 \\
\hline A3 & 125 & Clear & None & $1: 44: 6$ & 58,6 \\
\hline A4 & 200 & Clear & None & $1: 45: 1$ & 55,4 \\
\hline B1 & 50 & Clear & None & $0: 59: 1$ & 78,7 \\
\hline $\mathrm{B} 2$ & 75 & Clear & None & $0: 49: 4$ & 70,5 \\
\hline B3 & 125 & Clear & None & $0: 46: 4$ & 61,4 \\
\hline $\mathrm{C} 1$ & 50 & Clear & None & 0:38:1 & 79,5 \\
\hline $\mathrm{C} 2$ & 75 & Clear & None & $0: 32: 2$ & 72,6 \\
\hline $\mathrm{C} 3$ & 125 & Clear & None & $0: 51: 3$ & 56,0 \\
\hline $\mathrm{C} 4$ & 200 & Clear & None & $0: 41: 2$ & 39,4 \\
\hline D1 & 50 & Clear & None & $0: 20: 5$ & 75,5 \\
\hline D2 & 75 & Clear & None & $0: 25: 1$ & 74,5 \\
\hline D3 & 125 & Clear & None & $0: 20: 2$ & 55,5 \\
\hline D4 & 200 & Clear & None & $0: 30: 2$ & 43,8 \\
\hline E2 & 75 & Clear & None & $0: 32: 9$ & 74,0 \\
\hline E3 & 125 & Clear & None & $0: 39: 1$ & 59,5 \\
\hline E4 & 200 & Clear & None & 0:38:1 & 54,6 \\
\hline F1 & 50 & Clear & None & $0: 23: 8$ & 79,6 \\
\hline $\mathrm{F} 2$ & 75 & Clear & None & $0: 30: 9$ & 86,1 \\
\hline F3 & 125 & Clear & None & $0: 38: 8$ & 52,1 \\
\hline F4 & 200 & Clear & None & $0: 37: 2$ & 34,2 \\
\hline
\end{tabular}

emulsification time and the percentage of transmittance parameters, the composition with fast emulsification time is $<15 \mathrm{~s}$ and percentage transmittance more than $95 \%$ is formula A (VCO: Tween $80: \mathrm{PG}=1: 7: 2$ ) and $\mathrm{E}$ (Migltiol: Tween 80:PG=1:8:1).

Emulsification time is known as important parameters to describe system stability and prepare emulsification in the gastric fluid characteristic of SNEDDS. The purpose of measuring percent transmittance is to observe the self-emulsification process by measuring the transmittance of the solution during dissolution when the emulsification process takes place.

Singawalang leaves extract up to a dose of $200 \mathrm{mg} / 5 \mathrm{~mL}$ can be entrapped in globules. It can be seen that in the visual observation, the formula remains clear and there is no sediment. The selected SNEDDS formulation was stable for 6 months at room temperature. Another study stated that SNEDDS of Plantago lanceolata was stable for 1 month at room temperature [19].

The range of particle size of all selected formulations is between 13 $\mathrm{nm}$ and $18,7 \mathrm{~nm}$. The size meets the nano criteria and approaches the DNA size of about $10 \mathrm{~nm}$ [20]. The range of particle sizes in the study of SNEDDS formulations containing $P$. lanceolata was between 141,51 and 374,89 [19], while in the study of SNEDDS A, compactum, particle size was 13,97 [18]. The average droplet size of tetrandine SNEDDS was $19.75 \mathrm{~nm}$. The composition of SNEDDS formulation in this research consists of $40 \%$ (w/w) oleic acid as oil, 15\% (w/w) SPC, and 30\% (w/w) cremophor RH40 as surfactant, and 15\% (w/w) PEG400 as cosurfactant [21].

Droplet size is an important factor in SNEDDS formulation because it determines the level and rate of drug release and absorption and increases in bioavailability as well there in vivo stability smaller droplets have a larger surface area, which then increases the level of drug release. The small droplet size may be due to increased surfactant concentration, which forms a closed layer of surfactant at the interface, so as to stabilize dispersed droplets [22]. Therefore, in this study, the nanosize of SNEDDS Singawalang leaves extract might allow it to be more easily delivered into cells or to pass across some barriers.

The carrier oil positively affects the formation of droplet size, and surfactant causes the interfacial film to stabilize and condense.
Table 5: The mean of droplet size and the polydispersity index of self-nanoemulsifying drug delivery system extract Singawalang leaves

\begin{tabular}{lll}
\hline Formula & Droplet size mean $(\mathbf{n m})$ & Polydispersity index \\
\hline A4 & $13 \pm 0,8$ & 0,055 \\
B4 & $14.4 \pm 0,6$ & 0,006 \\
C4 & $13 \pm 1,1$ & 0,126 \\
D4 & $18,7 \pm 0,9$ & 0,004 \\
E4 & $13,4 \pm 0,9$ & 0,195 \\
F4 & $17,8 \pm 1,1$ & 0,249 \\
\hline
\end{tabular}

The polydispersity index of the $B$ formulation (VCO: Tween $80: P G=1: 8: 1$ ) was 0,006 and in the $\mathrm{D}$ formulation (Miglitol: Tween $80: \mathrm{PG}=2: 5: 3$ ) was 0,004 . This data show that the system had a narrow size distribution and homogeneity. Polydispersity index is the measure of globule size homogeneity. A value closer to zero, more homogeneous are the particles. The research of Embelin SNEDDS formulation showed that the polydispersity index was found to be $0,15 \pm 0,02-0,23 \pm 0,04$ [23]. The mean droplet size and polydispersity index in myricetin SNEDDS were $<200 \mathrm{~nm}$ with narrow distribution $(<0,4)[15]$.

The electron microscope images in this study showed a spherical nanoemulsion droplet, measuring $<100 \mathrm{~nm}$. A similar morphology of droplet image has been shown in several previous studies such as SNEDDS curcumin and myricetin $[15,24]$. Spherical, discrete, and nonaggregate clots in the SNEDDS formulation deduce system stability [25].

Future prospects of SNEDDS Singawalang leave extract to have the potential to increase biological activity and overcome the shortcomings of herbal medicines. The latest new challenges in the development of nanotechnology-based drug delivery systems include the feasibility of scale-up process that brings innovative therapeutic techniques to market quickly and the possibility of obtaining a multifunctional system to meet several biological and therapeutic requirements.

At present, health-care costs must also be considered. This reduction in health-care costs is likely to be obtained by increasing nanotherapeutic efficacy, reducing its length hospitalization, reducing personal healthcare costs, and effective treatment of major expensive diseases [26]. 
Subsequent studies must be conducted to determine the factors that lead to increased delivery efficiency and bioavailability.

\section{CONCLUSION}

In the present study, SNEDDS of extract Singawalang leaves was successfully developed. The optimum composition of this system was VC0: Tween 80:PG with a ratio at 1:8:1 and miglitol: Tween 80:PG with a ratio at $2: 5: 3$.

\section{ACKNOWLEDGMENT}

This research was support by the Ministry of Research, Technology and Higher Education of the Republic of Indonesia (Grant no 004/ADD/ SP2H/LT/DRPM/VII/2017). The authors are thankful to Ronny Marten from the Department of Biopharmaceutics, Faculty of Pharmacy of Universitas Gadjah Mada, Yogyakarta, for laboratory use guidance and licensing.

\section{AUTHORS' CONTRIBUTIONS}

Arifa Mustika conceived of the presented idea, developed the theory, and performed the research. Nurmawati Fatimah and Gadis Meinar Sari have carried out the research. All authors discussed the results and contributed to the final manuscript. Arifa Mustika wrote the manuscript with support from Nurmawati and Gadis.

\section{CONFLICTS OF INTEREST}

The authors declare that there are no conflicts of interest regarding the publication of this paper.

\section{REFERENCES}

1. Barbosa-Filho JM, Vasconcelos TH, Alencar AA, Batista LM, Oliveira RA, Guedes DN, et al. Plants and their active constituents from South, central, and North America with hypoglycemic activity. Braz J Pharmacogn 2005; 15:392-413.

2. Domínguez DR, Heredia LB, Martínez EC, Lores RI. Efecto del extracto hipoglicemeante de petiveria alliacea 1 sobre el consumo de glucosa por los eritrocitos. Rev Cubana Invest Biomed 2002;21:161-6.

3. Mustika A, Indrawati R, Sari GM. Effect of Petiveria alliacea leaves extracts in decreasing serum level of blood glucose level through activation of AMPK- $\alpha 1$ in diabetes mellitus rat models. Indones J Clin Pharm 2017;6:22-31

4. Kumar R, Sharma M. Herbal nanomedicine interactions to enhance pharmacokinetics, pharmacodynamics, and therapeutic index for better bioavailability and biocompatibility of herbal formulations. J Mater Nanosci 2018;5:35-58.

5. Watkins R, Wu L, Zhang C, Davis RM, Xu B. Natural product-based nanomedicine: Recent advances and issues. Int $\mathrm{J}$ Nanomedicine 2015;10:6055-74.

6. Sundari, Zuprizal, Yuwanta T, Martien R. Formulation nanocapsule of turmeric extract characterization on oral administration and its ability as antibacterial. Int J Sci Eng Res 2014;5:1261-5.

7. $\mathrm{Mg} \mathrm{K}, \mathrm{Krenn} \mathrm{V}$, Huebner F. History and possible uses of nanomedicine based on nanoparticles and nanotechnological progress. J Nanomed Nanotechnol 2015;6:06.
8. Mamillapalli V, Atmakuri AM, Khantamneni P. Nanoparticles for herbal extracts. Asian J Pharm 2016;10:54.

9. Martien R, Adhyatmika A, Irianto ID, Farida V, Sari DP. Technology developments nanoparticles as drug delivery systems. Majalah Farmaseutik 2012;8:133-44.

10. Ober CA, Gupta RB. Nanoparticle technology drug delivery. Idea@s CONCYTEG 2011;6:714-26.

11. Meena KP, Dangi PK, Kumar M. Nanoparticles technology and recent advances in novel drug delivery systems. Int J Res Drug Deliv 2011;1:1-5.

12. Balakumar K, Raghavan CV, selvan NT, prasad RH, Abdu S. Self nanoemulsifying drug delivery system (SNEDDS) of rosuvastatin calcium: Design, formulation, bioavailability and pharmacokinetic evaluation. Colloids Surf B Biointerfaces 2013;112:337-43.

13. Bonifácio BV, Silva PB, Ramos MA, Negri KM, Bauab TM, Chorilli M, et al. Nanotechnology-based drug delivery systems and herbal medicines: A review. Int J Nanomedicine 2014;9:1-5.

14. Liu C, Lv L, Guo W, Mo L, Huang Y, Li G, et al. Self-nanoemulsifying drug delivery system of tetrandrine for improved bioavailability: Physicochemical characterization and pharmacokinetic study. Biomed Res Int 2018;2018:6763057.

15. Qian J, Meng H, Xin L, Xia M, Shen H, Li G, et al. Self-nanoemulsifying drug delivery systems of myricetin: Formulation development, characterization, and in vitro and in vivo evaluation. Colloids Surf B Biointerfaces 2017;160:101-9.

16. Avachat AM, Patel VG. ZSPJ: The official publication. Saudi Pharm Soc 2015;23:276-89.

17. Amato S, Liu X, Zheng B, Cantley L, Rakic P, Man HY, et al. AMPactivated protein kinase regulates neuronal polarization by interfering with PI 3-kinase localization. Science 2011;332:247-51

18. Ujilestari T, Martien R, Ariyadi B, Dono ND, Zuprizal. Self-nano emulsifying drug delivery system [SNEDDS] of Amomum compactum essential oil: Design, formulation, and characterization. J Appl Pharm Sci V 2018;8:14-21.

19. Kalantari A, Kósa D, Nemes D, Ujhelyi Z, Fehér P, Vecsernyés M, et al. Self-nanoemulsifying drug delivery systems containing Plantago lanceolata an assessment of their antioxidant and antiinflammatory effects. Molecules 2017;22:E1773.

20. Boulaiz H, Alvarez PJ, Ramirez A, Marchal JA, Prados J, RodríguezSerrano F, et al. Nanomedicine: Application areas and development prospects. Int J Mol Sci 2011;12:3303-21

21. Liu C, Lv L, Guo W, Mo L, Huang Y, Li G, et al. Self-nanoemulsifying drug delivery system of tetrandrine for improved bioavailability: Physicochemical characterization and pharmacokinetic study. BioMed Res Int 2018;2018:1-10.

22. Zhang L, Zhang L, Zhang M, Pang Y, Li Z, Zhao A, et al. Selfemulsifying drug delivery system and the applications in herbal drugs. Drug Deliv 2015;22:475-86.

23. Parmar K, Patel J, Sheth N. Self nano-emulsifying drug delivery system for embelin: Design, characterization and in vitro studies. Asian J Pharm Sci 2015;10:396-404.

24. Joshi RP, Negi G, Kumar A, Pawar YB, Munjal B, Bansal AK, et al. SNEDDS curcumin formulation leads to enhanced protection from pain and functional deficits associated with diabetic neuropathy: An insight into its mechanism for neuroprotection. Nanomedicine 2013;9:776-85.

25. Kaur G, Chandel P, Harikumar SL. Formulation development of self nanoemulsifying drug delivery system [Snedds] of celecoxib for improvement of oral bioavailability. Pharmacophore 2013;4:120-33.

26. Chakraborty K, Shivakumar A, Ramachandran S. Nano-technology in herbal medicines: A review. Int J Herb Med 2016;4:21-7. 